\title{
Nonfatal Agricultural Injuries in Guinea: A Retrospective Descriptive Analysis
}

\author{
Keita Mamady ${ }^{*}$, Bin Zou ${ }^{2}$, Sylla Mafoule ${ }^{3}$ \\ ${ }^{1}$ Department of Epidemiology and Health Statistics, School of Public Health, Central South University, Changsha, \\ China \\ ${ }^{2}$ School of Geosciences and Info-Physics, Central South University, Changsha, China \\ ${ }^{3}$ School of Business, Central South University, Changsha, China \\ Email: ${ }^{*}$ kethmohawassdeh@gmail.com
}

Received 26 March 2014; revised 12 May 2014; accepted 22 May 2014

Copyright (C) 2014 by authors and Scientific Research Publishing Inc.

This work is licensed under the Creative Commons Attribution International License (CC BY).

http://creativecommons.org/licenses/by/4.0/

(c) (i)

\section{Abstract}

Objectives: Agricultural related injury has not been explored in Guinea. We aimed to describe the causes of agricultural related injury so as to improve safety practice on farms in Guinea. Methods: A retrospective descriptive analysis was made to present the nonfatal agricultural injuries in Guinea in 2012. Results: In 2012, 40,587 people (36.5/10,000 population) endured the agricultural injuries events in Guinea. The most important agents of injury in descending order included overexertion (30.2\%), cutting (22.9\%), motor vehicle accidents $(9.9 \%)$, venomous animal $(9.4 \%)$ and injury from animal $(9.0 \%)$. The entire male age groups exhibit the same major cause patterns of farming injury as female for overexertion and strenuous movements, cutting or piercing instrument or object and injury from animal. The reality is that female populations tend to sustained higher agricultural-related to motor vehicle accidents, but less venomous animal and agricultural machinery injuries than male populations. Also, female appeared to sustain hot, caustic, or corrosive object related injury than male except for male aged 65 years and over. Male as well as female aged over 65 years was highly exposed to fall than their younger counterparts. Males slightly bore higher morbidity than females ( 42.5 vs. $30.8 / 10,000$ population). Conclusions: Cutting or piercing instrument, motor vehicle accidents, venomous animal, and injury from animal which were held accountable for the majority of total injury morbidity risk factors in Guinea. The importance of agricultural risk factors differs by sex and age. Consequently, it is suggested that preventive intervention strategies should be accordingly tailored to reduce farm work-related injuries.

\section{Keywords}

Agriculture, Injury, Morbidity, Risk Factors, Guinea

\footnotetext{
${ }^{*}$ Corresponding author.
} 


\section{Introduction}

The farming has played a major role in human history, as farming progress has been a crucial factor in worldwide socio-economic change. Unfortunately, the farming production system also adversely affects the health and safety of many farmers around the world. About 170,000 farm workers are killed each year and millions more are either seriously injured in workplace accidents [1] [2]. Overseas studies in North America, Australia, and the United Kingdom place agriculture in the top four industries for fatal injury [3].

Generally, risk factors associated with nonfatal farm injuries can be categorized into two levels: 1) characteristics of the farm environment, and 2) characteristics of the farmer. Studies examining farm environment factors have reported that larger farms, farms with more workers, and farms with higher annual production were associated with higher injury risks for the farmer. With respect to individual risk factors for the farmer, a greater number of hours spent on the farm, full-time farm work, greater cumulative years of farm work experience, and male gender have shown positive associations with higher injury rates [4]. So far, among 20 recently reviewed studies of stress and occupational injuries, we found a statistically significant association $(P \leq 0.05)$ between stress and injuries, and 12 of the 17 studies with quantitative measures had odds ratios greater than 1.0, indicating that stress increased the risk of injuries [5]. Farm injuries also result in considerable physical and emotional disability and also in direct and indirect economic costs [6] [7].

After long years of being politically closed, Guinean national agricultural markets have developed thanks to the economic liberalization that began in the 1980s. Since that period, agriculture has been a policy priority for governments, reflecting its importance both in diversifying the economy, long dependent on mining, and in reducing poverty in rural areas, where most of the population live. Agriculture accounts for $24 \%$ of the total GDP and employs $84 \%$ of the economically active population, whether directly through food and fiber production and processing or indirectly through sales. Much, if not most, farm work, mainly manual in Guinea is performed by family members with women, children, and elderly routinely participating in arduous and hazardous tasks [8]-[11]. The occupational hazards of agriculture in industrialized countries are well documented, but there is very little information on those of under-developed countries, like Guinea [12]. In 2007, previous studies suggested that injury was the fifth leading cause of morbidity burden in Guinea, but we found no specific studies addressing safety in Guinean agriculture [13].

As with any public health problem, an important first step in preventing farm-related injuries from happening is to effectively document and track those individuals injured and to obtain detailed information about the causes [14]. The resulting finding implies that preventive efforts should be targeted at the underlying risk factors of the farming injuries as such a strategy would improve the cost-effectiveness of the efforts. This study is undertaken to describe the causes of agricultural related injury to improve safety practice on farms in Guinea.

\section{Methods}

\subsection{Data}

In this study, we made a retrospective analysis of hospitals records of patients presented at different national health facilities in Guinea with agriculture related injuries, from 01 January 2012 to 31 December 2012. Guinea's health system follows a pyramidal structure with approximately 850 health posts at the bottom, serving several villages each; about 400 health centers at the sub-prefecture level, which provide preventive and curative care and supervise the health posts; 26 prefecture hospitals; seven regional hospitals; and two national hospitals. The Ministry of Health oversees eight regional health directorates, which in turn oversee a total of 38 health prefectures/districts (three to six each). Each health post is staffed by an Agent Technique de Santé, a clinical officer with three years of training. Health centers are staffed by several clinicians, including midwives and doctors [15].

Individual records of farming related injury events were obtained from the department of health and occupational safety at the Guinean Ministry of Health. The records include record number, date and time of visit, date of birth, sex, circumstances and mechanism of injury, as well as discharge status and diagnoses. The data are routinely collected by physicians and nurses since they already have substantial knowledge of agricultural operations. Qualified statisticians from the Regional and Prefectural Health Departments are responsible for supervising the data collection systems. Data are then sent to the National Ministry of Public Health for storage after validation. Guinea's population was estimated to be 11,121,231 inhabitants in 2012, on the basis of estimates of 
the 1996 census [15].

Responses for external cause of injury were classified according to the International Classification of Diseases, 9th revision (ICD-9). ICD-9-CM E-codes used in this analysis included E927 (overexertion and strenuous movements), E919 (agricultural machinery), E880-888 (accidental falls), E828, 906 (injury from animal), E916-918 (striking or struck by objects or persons), E920 (cutting or piercing instrument or object), E810-829 (motor vehicle accidents), E905 (venomous animal or plant), E900 (hot, caustic, or corrosive object), and E928 (other) [16].

An injury episode was defined as "an unintentional injury that is serious enough to limit the normal activities of a person". A farm-related injury was defined as any injury that occurred on a farm, plot or ranch and resulted from an event related to agricultural production. The child did not need to reside on or be working on the farm to be included. A farm was defined as "any farm, ranch or other agricultural holding that produces at least one of the following agricultural products intended for sale or not: crops, livestock, poultry, animal products, or honey."

\subsection{Analysis}

We made use of the morbidity rates to ascertain the extent of farming related injury, calculated as the number of injury case divided by the population size $\times 10,000$. The age groups in the analysis were $0-14,15-24,25-64$, and $65+$ years. The external causes comprised overexertion and strenuous movements, agricultural machinery, accidental falls, injury from animal, striking or struck by objects or persons, cutting or piercing instrument or object, motor vehicle accidents, venomous animal or plant, hot, caustic, or corrosive object, and others (the remainder of causes). The nine commonest external causes were assessed in order to highlight the most important risk factors for each sex- and age-specific group.

\section{Results}

In 2012, 40,587 people (36.5/10,000 population) endured the agricultural injuries events in Guinea (Table 1). Having identified injury among all age groups, we noticed a gradual decrease in injury rates, with 65 years and over population ranking high in morbidity rate (72.1/10,000 population) followed by the 25 - 64 years old age group (46.7/10,000 population) and people aged between 25 - 64 years old (45.8/10,000 population). Children aged 14 and under carried the lowest nonfatal agricultural injury rate (22.1/10,000 population) (Table 1$)$.

Taking notice of the entire population, overexertion and strenuous movement (30.2\%), cutting or piercing instrument or object (22.9\%), motor vehicle accidents (9.9\%), venomous animal or plant (9.4\%) and injury from animal (9.0\%) were the most important agents of agricultural injury since they already account for $81.4 \%$ of the total percentage (Table 1).

Male age groups somewhat showed the same patterns of farming injury events with predominant causes of agricultural injury being overexertion and strenuous movements, cutting or piercing instrument or object, venomous animal or plant and injury from animal, except that venomous animal or plant were not prevalent for 15 to 25 age group. Contrary to the remaining age group, Guinean male residents aged 15 - 24 years were much more exposed to agricultural machinery where those over 65 years old additionally suffered from fall (Figure 1).

Although the entire male age groups exhibit the same major cause patterns of farming injury as female for overexertion and strenuous movements, cutting or piercing instrument or object and injury from animal, the reality is that female populations tend to sustained higher agricultural-related to motor vehicle accidents, but less venomous animal and agricultural machinery injuries than male. Also, female appeared to sustain hot, caustic, or corrosive object related injury than male except for male aged 65 years and over. Furthermore, like male aged over 65 years, older female was also highly exposed to fall (Figure 2).

\section{Discussion}

First of its kind, this study was undertaken to determine the major risk factors which contributed to agricultural injury in Guinea in 2012. The agriculture related injury morbidity rate was 36.7/10,000 population; males slightly bore higher morbidity than females (42.5 vs. 30.8/10,000 population); all age groups were subject to farming injury, with rates ranging from 22.1 to 72.1/10,000 population; overexertion, cutting or piercing instru- 
Table 1. Morbidity from farming injuries in Guinea, 2012.

\begin{tabular}{|c|c|c|}
\hline Demographics & Number of cases (\%) & Morbidity/10,000 \\
\hline Total & $40,587(100 \%)$ & 36.5 \\
\hline \multicolumn{3}{|l|}{ Sex } \\
\hline Male & $23,066(56.8 \%)$ & 42.5 \\
\hline Female & $17,521(43.2 \%)$ & 30.8 \\
\hline \multicolumn{3}{|l|}{ Age group } \\
\hline $0-14$ & $11,176(27.5 \%)$ & 22.1 \\
\hline $15-24$ & $8396(20.7 \%)$ & 45.8 \\
\hline $25-64$ & 17,295 (42.6\%) & 46.7 \\
\hline $65+$ & $3720(9.2 \%)$ & 72.1 \\
\hline \multicolumn{3}{|l|}{ Injury external causes } \\
\hline Overexertion and strenuous movements & $12,270(30.2 \%)$ & 11.0 \\
\hline Agricultural machinery & 2191 (5.4\%) & 2.0 \\
\hline Accidental falls & $2742(6.8 \%)$ & 2.5 \\
\hline Injury from animal & $3635(9.0 \%)$ & 3.3 \\
\hline Striking or struck by objects or persons & $641(1.6 \%)$ & 0.6 \\
\hline Cutting or piercing instrument or object & 9297 (22.9\%) & 8.4 \\
\hline Motor vehicle accidents & $4026(9.9 \%)$ & 3.6 \\
\hline Venomous animal or plant & $3833(9.4 \%)$ & 3.4 \\
\hline Hot, caustic, or corrosive object & $1204(3.0 \%)$ & 1.1 \\
\hline Other & 748 (1.8\%) & 0.7 \\
\hline
\end{tabular}

ment, motor vehicle accidents, venomous animal, and injury from animal were the five important causes of agricultural injury for the whole population, accounting for $81.4 \%$.

When compared to injury rates reported by other studies for other countries, the rates reported here (36.6/10,000 population) appeared to be low. The typical reported nonfatal injury rate among farmers in industrialized countries is around 20/100 [17]-[20]. The reason for these discrepancies in rates might be explained by differences in agricultural injury surveillance systems. Despites the lack of data on agricultural injuries, especially nonfatal injuries, which has been recognized as a problem by a number of researchers, developed countries over the time have had a depth of experience in building strong functional systems to track agricultural injury, when in Guinea, less is known about the work-related injuries control system particularly of the rural people engaged in mostly nonmechanized agriculture [11] [21] [22].

In the present study, overexertion was the most common external cause. This observation supports the argument, commonly made by injury researchers that accidents do not happen inevitably and by random chance, but are associated with personal and environmental risk factors that may be modified to reduce risk. Our results are in harmony with those reported by a population-based telephone survey addressing farm-work-related injuries among California farm operators that overexertion was the most common cause of farming injuries [23]. To examine this issue in the specific context, overexertion might be due to the predominant reliance of African agriculture on human muscle power [24]-[26]. Additionally, overexertion might have also resulted from certain conditions that Guinea as well as other Sub-Saharan countries farming is subject to such as: a greater impact of global economy on farm size, more extensive participation of family members in the farming operation, seasonal time pressures, dependency on weather conditions, variation in climatic patterns and extending work hours [12]. 


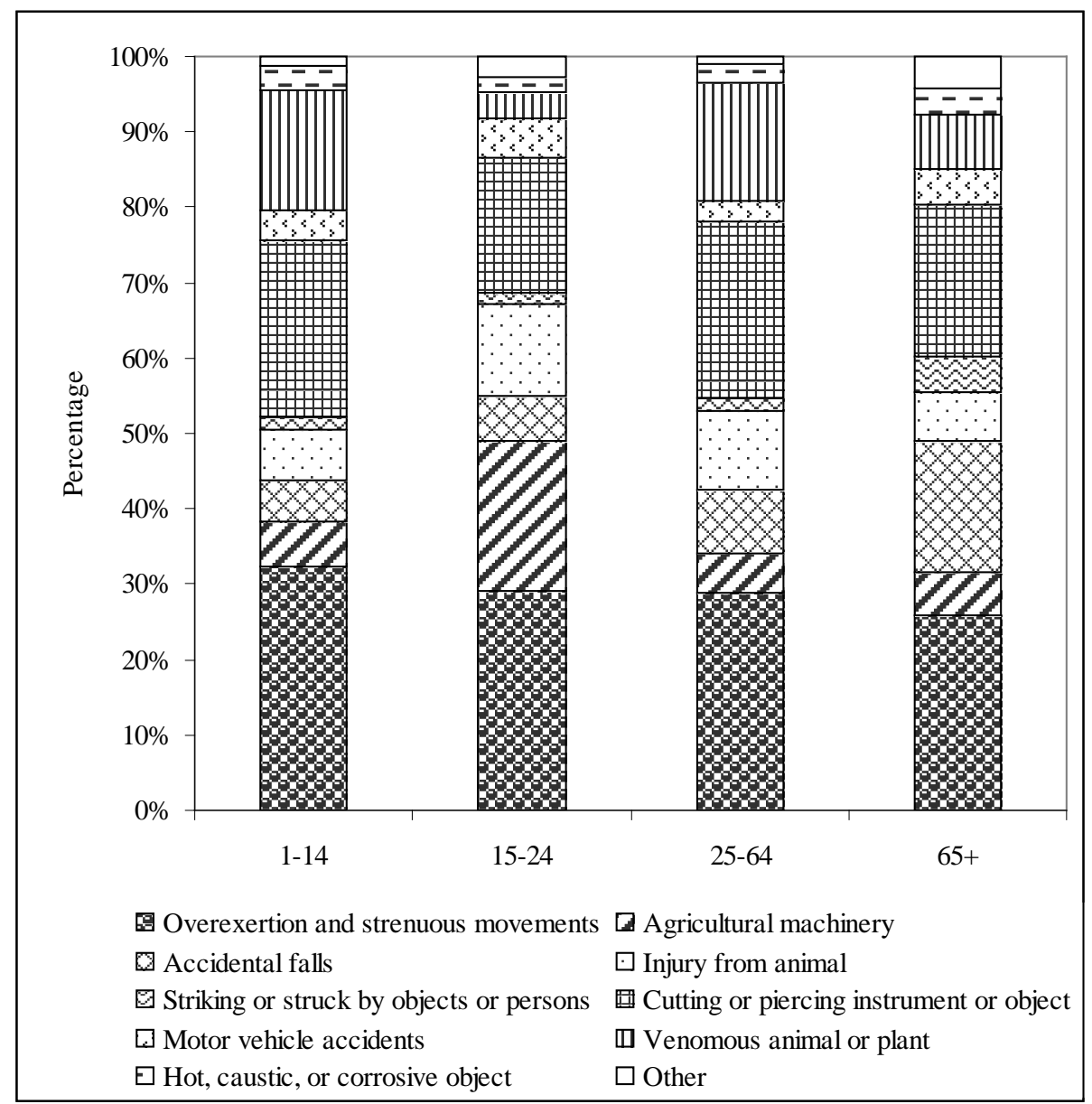

Figure 1. Percentage of external causes of farming injury for male by age group (Guinea, 2012).

Cutting or piercing instrument was another important risk factor. This finding may be explained by the combination of overexertion and high persistent reliance of African farming on hand tools [27]. This is in accordance with most of the existing literatures, which suggest that haste and fatigue in conjunction with heavy manual labor would contribute to injury risk [12] [28] [29].

Our data suggest that male experienced farming injury about 1.4 times than females, far smaller as compared to the finding reported elsewhere where male encountered about 6 times more than females [30]. The traditional roles of men in low socio-economic farmers which used to assigned farming task to male and engaged females in household chores are changing in Sub-Saharan Africa since population pressure and off-farm employment opportunities for men have led to an increasing proportion of women becoming de facto farm managers [31]. Other important points rose by this study is high exposure of Guinean male farmers to venomous animal, when female farmers incur considerable injury risk for hot objects and motor vehicle accident suggesting a difference in farm-related injuries and injury risks between male and female, possibly related to differences in exposure in farm work tasks, work patterns and work environments which is sustained by other studies [29] [32]. To some extent, these findings might be due to the fact that in Sub-Saharan Africa including Guinea, the agricultural productivity remains far short of potential, hindered by poverty, drought, low budget allocations to the sector, and in some cases, land degradation and socio-political turmoil. And there are few opportunities for income generation other than farming [33]. These disadvantageous situations make Guinean farmers poor. The financial pressure faced by many farmers impedes the adoption of health and safety behaviors, as financial survival becomes the major concern of the family. Poverty has been shown to be associated with inadequate insurance and poor health care [28]. 


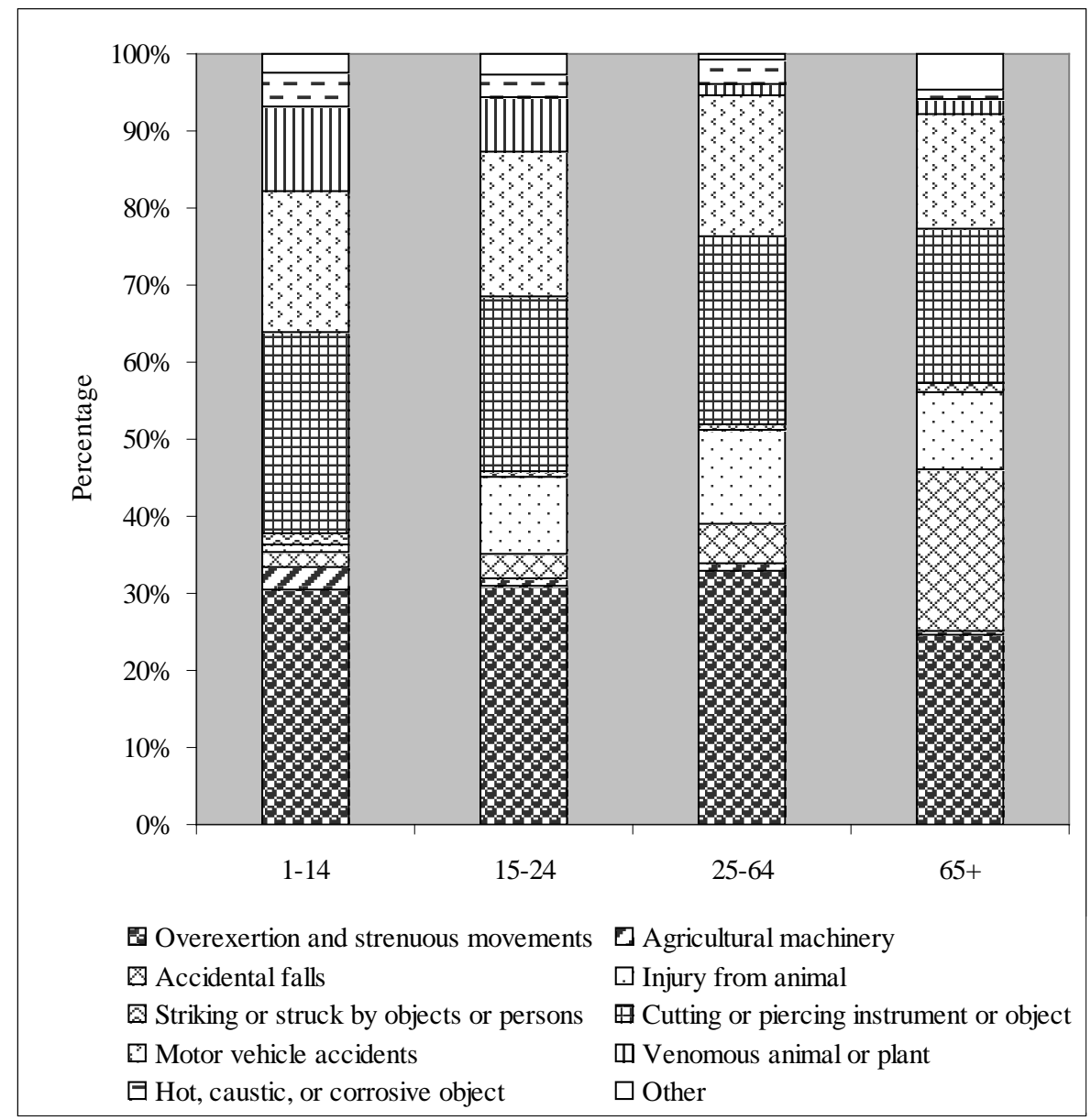

Figure 2. Percentage of external causes of farming injury for female by age group (Guinea, 2012).

Although agricultural injury affected almost all age groups because the entire family members worked together irrespective of age, hence there are almost equal chances of younger and older member of the family getting injured, those aged 65 and over had the highest rates. Moreover, this study's results come close to supporting the statement that some occupational injury risks vary with age. Both male and female over 65 years old suffered from fall than their younger counterparts. Some earlier studies also showed similar results, with falls common issue for older workers [4] [34]. Age-related conditions, such as arthritis, vision or hearing problems make farming potentially more dangerous for senior farmers [35] [36]. At the same time, more adolescent farmers were injured in risky activities than were the older ones [21]. This finding suggests that adolescent farmers are more involved in certain kinds of high risk agricultural activities (such as those related to machinery), which increase the frequency and degree of exposure to hazards in farming. In spite of the fact that adolescent farmers lack training and experience and/or that they are greater risk takers in operating machines on the farm. What is more, it is recognized that most farm machines in Guinea as well as in most part in Africa are imported and these are not specially designed to operate in the various Africa regions' specific agro-ecological conditions. In general, they are imported without any standardized testing and evaluation. In addition, it is realized that many of locally manufactured agricultural implements in Africa are of substandard quality. Add to these are insufficient knowledge about management system for repair, maintenance and replacement parts. As a result, low quality machinery leads to financial losses and at times is also unsafe for operation in the fields. Another attribute of machine injury is the usage pattern. So the machine injury victims such as tractor are not only operators but also passengers and occupants of other vehicles [9] [37].

The data in this paper could underestimate the total rate of farm injuries in Guinea because the study 
represents only cases requiring admission to health facilities across the country. The lack of a uniform definition for farm-related injury at the national level may have been one of the reasons of underreporting. Secondly, hospital-based data capture the population whose injuries are serious enough to merit admission to hospital. Thirdly, due to the high cost of medical interventions, more and more people began to look to the traditional practitioners for alternatives [31]. This study is also limited by the coding practice which may differ by hospital resulting in a systematic bias in the farming injury coding rate for a given event.

Based on the study findings the following measures are recommended: a legislative regulation of the farm work environment should be formulated for the country; a central authority should be established and charged with responsibility for investigations, data collection, training, publications and prevention of the agricultural health and safety issues in the country; curricula should be developed for the training of farmers, agricultural and health professionals; surveillance systems should be developed to collect information on farm injuries. This could be implemented by including farm injury questions in the agricultural census and by training nurses to probe and collect farm injury and health data from rural patients, which they report to the department of health by the means of monthly reports; a multifaceted approach to increase the use of protective devices by farmers should be implemented; and raising awareness on the need and benefits of using them; more research on the health and safety of Guinean agricultural should be conducted; and interventions should be implemented and the effectiveness of policy, education and preventive approaches should be evaluated. Improvements to agricultural mechanization and the ergonomic conditions of hand tools should be instituted.

\section{Conclusion}

In short, this study has revealed that the risk factors such as overexertion, cutting or piercing instrument, motor vehicle accidents, venomous animal, and injury from animal which were held accountable for the majority of total injury morbidity risk factors in Guinea. The importance of agricultural risk factors differs by sex and age. Consequently, suggest preventive intervention strategies should be accordingly tailored to reduce farm workrelated injuries.

\section{Acknowledgements}

This work was supported by Department of Health and Occupational Safety at the Guinean Ministry of Health, Fundamental Research Funds for the Central Universities of Central South University (2012zzts029) and Hunan Province Innovation Projects (CX2012B076) of China. The data used in this study were exempt from Institutional Review Board approval.

\section{Author Disclosure Statement}

No competing interest declared.

\section{Funding}

The study was supported by the Fundamental Research Funds for Central South University (2012zzts029) and the Hunan Province Innovation Projects (CX2012B076) of China. This work was also supported by Department of Health and Occupational Safety at the Guinean Ministry of Health.

\section{References}

[1] Rhee, K.Y., Choe, S.W., Kim, Y.S., et al. (2013) The Trend of Occupational Injuries in Korea from 2001 to 2010. Safety and Health at Work, 4, 63-70. http://dx.doi.org/10.5491/SHAW.2013.4.1.63

[2] Lower, T., Fragar, L. and Temperley, J. (2011) Agricultural Health and Safety Performance in Australia. Journal of Agromedicine, 16, 292-298. http://dx.doi.org/10.1080/1059924X.2011.605726

[3] Horsburgh, S., Feyer, A.-M. and Langley, J.D. (2001) Fatal Work Related Injuries in Agricultural Production and Services to Agriculture Sectors of New Zealand, 1985-94. Occupational and Environmental Medicine, 58, 489-495. http://dx.doi.org/10.1136/oem.58.8.489

[4] Browning, S.R., Truszczynska, H., Reed, D. and McKnight, R.H. (1998) Agricultural Injuries among Older Kentucky Farmers: The Farm Family Health and Hazard Surveillance Study. American Journal of Industrial Medicine, 33, 341353. http://dx.doi.org/10.1002/(SICI)1097-0274(199804)33:4<341::AID-AJIM4>3.0.CO;2-X 
[5] Julià, M., Catalina-Romero, C., Calvo-Bonacho, E., et al. (2013) The Impact of Job Stress Due to the Lack of Organisational Support on Occupational Injury. Occupational and Environmental Medicine, 70, 623-629. http://dx.doi.org/10.1136/oemed-2012-101184

[6] Angoules, A.G., Lindner, T., Vrentzos, G., et al. (2007) Prevalence and Current Concepts of Management of Farmyard Injuries. Injury, 5, S27-S34.

[7] Litchfield, M.H. (1999) Agricultural Work Related Injury and Ill-Health and the Economic Cost. Environmental Science and Pollution Research, 6, 175-182. http://dx.doi.org/10.1007/BF02987623

[8] Ministry of Planning and Cooperation (1995) Permanent and Ultimate Household Survey of Living Conditions of Households with Budget Module and Consumption: A Profile of Poverty in Guinea. Comprehensive Consumption Budget Survey, 1994-1995. Project to Support the Socioeconomic Development. Conakry, Republic of Guinea.

[9] (2004) Report of the Agricultural Census of Guinea 2000/2001, National Service of Agricultural Statistics. Ministry for the Agriculture, Livestock, Water and Forest, Guinea,

[10] National Directorate of Statistics, Ministry of Planning and Cooperation (1998) Full Inquiry into the Living Conditions of Households with Budget Module and Consumption 1994-1995. Conakry, Republic of Guinea.

[11] National Directorate of Statistics (Guinean Ministry of Planning and Cooperation) and ORC Macro (2006) Demographic and Health Survey, Guinea in 2005. DNS and ORC Macro, Calverton.

[12] Rex, K., Kelley, D., Shannon, M., et al. (2006) Agricultural Health in the Gambia II: A Systematic Survey of Safety and Injuries in Production Agriculture. Annals of Agricultural and Environmental Medicine, 13, 119-128.

[13] Mamady, K. and Hu, G. (2011) A Step Forward for Understanding the Morbidity Burden in Guinea: A National Descriptive Study. BMC Public Health, 11, 436. http://dx.doi.org/10.1186/1471-2458-11-436

[14] Sheila, H., Tanya, B. and Herbert, G. (2011) Garrison. Injury and Death on the Farm: Improving Prevention through Improved Surveillance. North Carolina Medical Journal, 72, 461-465.

[15] Department of National Health Information, Ministry of Public Health of Guinea (2008) Guinean Annual Health Statistics Report 2009. The Ministry of Public Health of Guinea, Conakry.

[16] World Health Organization (1977) International Classification of Diseases: Manual of the International Statistical Classification of Diseases, Injuries, and Causes of Death. 9th Revision, World Health Organization, Geneva.

[17] Helitzer, D., Willging, C., Hathorn, G. and Benally, J. (2009) Using Logic Models in a Community-Based Agricultural Injury Prevention Project. Public Health Reports, 124, 63-73.

[18] Zhu, H.P., Xia, X., Xiang, H.Y., Yu, C.H. and Du, Y.K. (2012) Disability, Home Physical Environment and Non-Fatal Injuries among Young Children in China. PLOS ONE, 7, Article ID: e37766. http://dx.doi.org/10.1371/journal.pone.0037766

[19] Rautiainen, R.H., Lange, J.L., Hodne, C.J., Schneiders, S. and Donham, K.J. (2004) Injuries in the Iowa Certified State Farm Study. Journal of Agricultural Safety and Health, 10, 51-63. http://dx.doi.org/10.13031/2013.15674

[20] Rautiainen, R.H., Ohsfeldt, R., Sprince, N.L., Donham, K.J., Burmeister, L.F., Reynolds, S.J., Saarimäki, P. and Zwerling, C. (2005) Cost of Compensated Injuries and Occupational Diseases in Agriculture in Finland. Journal of Agromedicine, 10, 21-29. http://dx.doi.org/10.1300/J096v10n03_03

[21] Zhou, C. and Roseman J.M. (1994) Agricultural Injuries among a Population-Based Sample of Farm Operators in Alabama. American Journal of Industrial Medicine, 25, 385-402. http://dx.doi.org/10.1002/ajim.4700250307

[22] Donham, M. and Thelin, A. (2006) Agricultural Medicine: Occupational and Environmental Health for the Health Professions. Blackwell, Ames.

[23] McCurdy, S.A., Farrar, J.A., Beaumont, J.J., Samuels, S.J., Green, R.S., Scott, L.C. and Schenker, M.B. (2004) Nonfatal Occupational Injury among California Farm Operators. Journal of Agricultural Safety and Health, 10, $103-119$. http://dx.doi.org/10.13031/2013.16070

[24] Douphrate, D.I., Stallones, L., Kolstrup, C.L., Nonnenmann, M.W., Pinzke, S., Hagevoort, G.R., Lundqvist, P., Jakob, M., Xiang, H.Y., Xue, L., Jarviei, P., McCurdy, S.A., Reed, S. and Lower, T. (2013) Work-Related Injuries and Fatalities on Dairy Farm Operations-A Global Perspective. Journal of Agromedicine, 18, 256-264. http://dx.doi.org/10.1080/1059924X.2013.796904

[25] Naidoo, S., London, L., Rother, H.A., Burdorf, A., Naidoo, R.N. and Kromhout, H. (2010) Pesticide Safety Training and Practices in Women Working in Small-Scale Agriculture in South Africa. Occupational and Environmental Medicine, 67, 823-828. http://dx.doi.org/10.1136/oem.2010.055863

[26] Naidoo, S., Kromhout, H., London, L., Naidoo, R.N. and Burdorf, A. (2009) Musculoskeletal Pain in Women Working in Small-Scale Agriculture in South Africa. American Journal of Industrial Medicine, 52, 202-209. http://dx.doi.org/10.1002/ajim.20662

[27] Schlüter, E. and Heuser, K. (1998) Dramatic Development of Quadriplegia in a Young Man While Engaged in Heavy 
Manual Labour: A Post-Traumatic Spinal Cord Injury. Virchows Archiv, 433, 487-491. http://dx.doi.org/10.1007/s004280050278

[28] Xiang, H.Y., Wang, Z.Z., Stallones, L., Keefe, T.J., Huang, X.Z. and Fu, X.H. (2000) Agricultural Work-Related Injuries among Farmers in Hubei, People's Republic of China. American Journal of Public Health, 90, 1269-1276. http://dx.doi.org/10.2105/AJPH.90.8.1269

[29] Schulman, M.D., Evensen, C.T., Runyan, C.W., Cohen, L.R. and Dunn, K.A. (1997) Farm Work Is Dangerous for Teens: Agricultural Hazards and Injuries among North Carolina Teens. Journal of Rural Health, 13, 295-305. http://dx.doi.org/10.1111/j.1748-0361.1997.tb00972.x

[30] Cohen, L.R., Runyan, C.W., Dunn, K.A. and Schulman, M.D. (1996) Work Patterns and Occupational Hazard Exposures of North Carolina Adolescents in 4-H Clubs. Injury Prevention, 2, 274-277. http://dx.doi.org/10.1136/ip.2.4.274

[31] Baldé, M.C., Mané, Y. and Trape, J.F. (2009) Epidemiological Study of Poisonous Snakes and Management of Envenomation in Kindia (Republic of Guinea). Medecine Tropicale, 69, 37-40.

[32] Stueland, D.T., Lee, B.C., Nordstrom, D.L., Layde, P.M. and Wittman, L.M. (1996) A Population Based Case-Control Study of Agricultural Injuries in Children. Injury Prevention, 2, 192-196. http://dx.doi.org/10.1136/ip.2.3.192

[33] Davis, M.S., Farnworth, C. and Sundell, M.F. (2012) Transforming Gender Relations in Agriculture in Sub-Saharan Africa: Promising Approaches. SIANI Stockholm Environment Institute Kräftriket 2B SE-106 91 Stockholm Sweden. http://www.sei-international.org/mediamanager/documents/Publications/SEI-DiscussionBrief-SIANI-TransformingGe nderRelationsInAgricultureInSubSaharanAfricaPromisingApproaches-2012.pdf

[34] Hartman, E., Frankena, K., Oude Vrielink, H., Nielen, M., Metz, J. and Huirne, R. (2004) Risk Factors Associated with Sick Leave Due to Work-Related Injuries in Dutch Farmers: An Exploratory Case-Control Study. Safety Science, 42, 807-823. http://dx.doi.org/10.1016/j.ssci.2004.03.001

[35] Hartling, L., Pickett, W. and Brison, R.J. (1997) Non-Tractor, Agricultural Machinery Injuries in Ontario. Canadian Journal of Public Health, 88, 32-35.

[36] Franklin, R.C., Depczynski, J., Challinor, K., Williams, W. and Fragar, L.J. (2006) Factors Affecting Farm Noise during Common Agricultural Activities. Journal of Agricultural Safety and Health, 12, 117-125. http://dx.doi.org/10.13031/2013.20388

[37] UNIDO and FAO (2007) Agricultural Mechanization in Africa for Enhanced Productivity: A Call for Action. Proceedings of a UNIDO-FAO Workshop, Vienna. 